\title{
A FORMAÇÃO DA MENSAGEM NA COMUNICAÇÃO ENTRE CUIDADORES E IDOSOS COM DEMÊNCIA ${ }^{1}$ MESSAGE FORMATION IN COMUNICATION BETWEEN CAREGIVERS AND ELDERLY WITH DEMENTIA LA FORMACIÓN DEL MENSAJE EN LA COMUNICACIÓN ENTRE CUIDADORES Y ANCIANOS CON DEMENCIA
}

\author{
Rosimere Ferreira Santana², Nébia Maria de Almeida Figueiredo33, Márcia Assunção Ferreira4, \\ Neide Aparecida Titonelli Alvim ${ }^{5}$
}

\footnotetext{
${ }^{1}$ Recorte ampliado da tese intitulada "A comunicação entre cuidadores principais e idosos com demência: implicações para o cuidado de enfermagem".

${ }^{2}$ Doutora em Enfermagem. Professora Adjunto do Departamento de Enfermagem Médico-Cirúrgico da Universidade Federal Fluminense (UFF). Rio de Janeiro, Brasil.

${ }^{3}$ Doutora em Enfermagem. Professora Titular da Escola de Enfermagem Alfredo Pinto da Universidade Federal do Estado do Rio de Janeiro. Pesquisadora do CNPp. Orientadora da tese. Rio de Janeiro, Brasil.

${ }^{4}$ Doutora em Enfermagem. Professora Titular do Departamento de Enfermagem Fundamental da Escola de Enfermagem Anna Nery (EEAN)/UFRJ. Co-orientadora da tese. Rio de Janeiro, Brasil.

${ }^{5}$ Doutora em Enfermagem. Professora Titular do Departamento de Enfermagem Fundamental da EEAN/UFRJ. Co-orientadora da tese. Rio de Janeiro, Brasil.
}

PALAVRAS-CHAVE: Enfermagem geriátrica. Cuidadores. Saúde do idoso. Comunicação. Transtornos da comunicação.

KEYWORDS: Geriatric nursing. Caregivers. Health of the elderly. Communication. Communication disorders.

PALABRAS CLAVES Enfermería geriátrica. Cuidadores.Salud delanciano. Comunicación. Trastornos de la comunicación.
RESUMO: Pesquisa qualitativa cujos objetivos foram: descrever a formação da mensagem entre cuidadores principais e idosos com demência; e analisar os fatores que conferem a efetividade da comunicação dos cuidadores. Aplicou-se o Método Criativo Sensível com duas dinâmicas de criatividade e sensibilidade, nas quais desenvolveram-se a discussão grupal, a observação participante e a produção de imagens no decorrer de oito encontros com 25 cuidadores que freqüentaram um Núcleo de Neurogeriatria da cidade do Rio de Janeiro, de agosto de 2005 a abril de 2006. Para a organização e tratamento dos dados utilizou-se a análise de discurso. Os resultados apontaram que a formação da mensagem do cuidador ao idoso se dá pela intencionalidade da ação desejada pelos cuidadores, levando em conta três fatores para sua construção: o conteúdo, o tratamento e o código. Isso implica que os profissionais da saúde, e em especial, as enfermeiras, orientem os cuidadores a se comunicarem efetivamente.

ABSTRACT: The objectives of this qualitative research are to describe message formation between caregivers and elderly with dementia and to analyze the factors that certify the caregivers' communication effectiveness. The Sensible Creative Method was applied in two creativity and sensitivity group dynamics which developed group discussion, participative observation, and image production in eight meetings with 25 Neurogeriatric Center caregivers, in Rio de Janeiro, RJ, Brazil from August, 2005 to April, 2006. Discourse analysis was used to organize and treat the data. The results pointed out that message formation from the caregiver to the elderly is affected through the intentionality of the caregivers' desired action, considering three factors in its construction: its content, its treatment, and its code. This implies that health care professionals, especially nurses, should orient caregivers in effective communication.

RESUMEN: Investigación cualitativa cuyos objetivos son: describir la formación del mensaje entre los cuidadores principales y los ancianos con demencia; $y$, analizar los factores que producen efectividad en la comunicación de los cuidadores. Para el estudio se empleó el Método Creativo Sensible con la realización de dos dinámicas de creatividad y sensibilidad, en las cuales se desarrollaron la discusión grupal, la observación participante y la producción de imágenes, en el transcurso de ocho encuentros con 25 cuidadores que frecuentan un Núcleo de Neurogeriatría, de la ciudad de Rio de Janeiro, en el período de agosto de 2005 a abril de 2006. Para el análisis de los datos se utilizó el análisis del discurso. Los resultados indicaron que la formación del mensaje del cuidador al anciano se produce por la intencionalidad de la acción deseada por los cuidadores, teniéndose en cuenta tres factores para su construcción: el contenido, la atención y el código. Eso significa que los profesionales de salud, y en especial, las enfermeras, orienten los cuidadores a comunicarse de manera efectiva.
Rosimere Ferreira Santana

Endereço: R. 13 Qd. 40 Lt.13 Cs. 02

24900-000 - Jardim Atlântico, Itaipuaçu, Maricá, RJ, Brasil.

E-mail: rosifesa@yahoo.com.br
Artigo original: Pesquisa

Recebido em: 15 de outubro de 2007 Aprovação final: 5 de maio de 2008 


\section{CONSIDERAÇÕES INICIAIS}

O termo demência vem do latim, dementia; de - mentia, significa ausência de mente, um estado irreversível e terminal, conceito herdado do século XVIII. No século XX, os estudos se concentraram na questão clínica e epidemiológica, o que repercutiu na mudança de sua denominação atual para transtorno cognitivo. A demência é tratada como uma síndrome, ou seja, um grupo de sinais e sintomas que formam um conjunto e que pode ser causada por uma série de doenças subjacentes, relacionadas a perdas neuronais e danos à estrutura cerebral, ou seja, um idoso com necessidades especiais. ${ }^{1}$

O cuidador principal é aquele que tem a total ou a maior responsabilidade pelos cuidados prestados ao idoso dependente no domicílio. E, usualmente, a denominação de cuidador informal é dada aos familiares, amigos e voluntários da comunidade. ${ }^{2}$ Esses, provavelmente, podem ter dificuldades não expressadas na comunicação com o idoso portador de transtorno cognitivo, que só poderá ser mais bem esclarecido com aprofundamentos investigativos.

Assim, o sujeito que sofre de síndrome demencial apresenta problemas na comunicação como, por exemplo: pensamento "concreto", um retardamento no tempo de resposta; problemas de memória; déficits sensoriais; e flutuações do pensamento. $^{3-6} \mathrm{Um}$ problema que implica no relacionamento entre ambos, pois às vezes o idoso com demência sequer responde, embora esteja olhando para o interlocutor, não sabemos o que ele vê, pois às vezes seu olhar é perdido e distante para quem cuida dele.

Portanto interessa-nos a comunicação entre cuidadores principais e idosos com demência e suas implicações para o cuidado no âmbito doméstico. Isso implica em investigar a formação da mensagem utilizada pelos cuidadores para se comunicarem efetivamente com o idoso. Nesse sentido, aplicou-se um referencial teórico ${ }^{7}$ que ressalta a importância dos conceitos de ruído e fidelidade da comunicação, compreendendo que o isolamento dos fatores envolvidos na comunicação determinam sua efetividade. Ruído na comunicação são os fatores que distorcem a qualidade do sinal emitido. E fidelidade é a tradução da mensagem com o máximo de exatidão. Portanto, são vários os elementos envolvidos no contexto da comunicação, especialmente neste estudo, naquele que envolve o idoso com demência e seu cuidador, considerando o déficit cognitivo desse idoso e a necessidade de habilidades comunicacionais dos cuidadores para atingir os objetivos da comunicação que devem ser analisados em relação ao processo de cuidar do idoso com demência.

Assim, buscamos responder a seguinte questão norteadora: como se dá a formação da mensagem dos cuidadores de idosos com demência? Para contemplar este questionamento, traçamos os seguintes objetivos: descrever a formação da mensagem entre cuidadores principais e idosos com demência; e analisar os fatores que conferem a efetividade da comunicação dos cuidadores junto ao idoso com demência.

No que diz respeito ao estado da arte encontrado na base de dados International Database for Medical Literature (MEDLINE), encontramos 1.123 estudos na área de demência, dos quais 421 são na área de enfermagem, obtendo 40 estudos concentrados na temática comunicação publicada entre 1997 a 2007, e mais quatro estudos que antecedem este período, porém de extrema relevância por serem os mais citados conforme busca na ferramenta Google Scholar. Dentre estes artigos, 33 relacionam-se de alguma forma com o objeto deste estudo, por enfocar a questão da comunicação com o idoso com demência em diversos cenários ou mesmo envolvendo diferentes sujeitos, mas nenhum relacionado diretamente com a comunicação entre este e o cuidador, no espaço doméstico.

Já através da BIREME foi possível acessar 467 estudos na área de demência. Pode existir uma margem de erro nesse número, pois o descritor demência é utilizado para descrever estudos na área de psiquiatria. Relacionando demência e enfermagem, foram encontrados 11 estudos, e dentre estes, 2 relacionados à esquizofrenia que foram excluídos. Não foram localizados na base Latin American and Caribbean Health Sciences (LILACS) pesquisas que relacionavam diretamente enfermagem, demência e comunicação, constituindo, uma necessidade de estudos aprofundados da comunicação existente entre o cuidador e idoso com demência.

No entanto, quando acessamos trabalhos sobre cuidadores de idosos, o número de produções aumenta para 18, observando-se uma concentração de estudos na sobrecarga dos cuidadores ou comumente conhecido como estresse dos cuidadores que discutem a problemática de se manter um idoso dependente em casa. Esses estudos são importantes na elucidação do cuidado não profissional na área de saúde do idoso, pois parece impossível que possamos nos comunicar 
bem quando estamos estressados, apressados ou impacientes, o que nos alerta para que tipo de comunicação seja possível construir na relação com idosos dementes.

A presença do cuidador como importante representante do cuidado leigo, revela a necessidade de uma melhor articulação dos profissionais de saúde contribuindo com seu bem-estar direto e indiretamente com o da pessoa por ele cuidado. Pode-se entender por "cuidador leigo", aquela pessoa dentro do sistema de cuidado popular, que reúne um conjunto de conhecimentos populares e habilidades culturalmente aprendidas e transmitidas para proporcionar ações de assistência, suporte, capacitação ou facilitação para ou por outro indivíduo, grupo ou instituição que manifesta ou prevê uma necessidade, com a finalidade de melhorar as incapacidades e situações de morte. ${ }^{8}$

Na realidade norte-americana, a maioria dos idosos é dependente e vive em instituições de longa permanência, portanto, sob cuidados profissionais. Nos países latino-americanos, grande parte desses idosos vive no seu domicílio sob os cuidados diretos de um cuidador leigo, em sua maioria, um membro da família. Esse é o grande responsável pela assistência do idoso em seu domicílio, seja pela deficiência de incentivos políticos, financeiros e de instituições que aceitem estes idosos, seja pela tradição cultural de manter estes idosos em casa, o que se justifica a importância de estudos que explorem esta problemática na perspectiva doméstica.

Com esta pesquisa, interessa-nos contribuir para o conhecimento do que, como e para quê ocorre a comunicação entre esses sujeitos, uma vez que os prejuízos da comunicação inerentes ao déficit cognitivo do idoso com demência podem interferir para a promoção de cuidado a este idoso, e podem ser úteis ao processo de ensino aprendizagem de profissionais da área gerontológica, assim como fornecer subsídios para futuras pesquisas afins.

\section{METODOLOGIA}

Dentre as formas qualitativas de se investigar, nos apropriamos de parte do Método CriativoSensível (MCS), ${ }^{9}$ pelo fato do mesmo permitir o trabalho em grupo. Respalda-se no conhecimento da práxis do ser humano no plano coletivo, no caso os cuidadores são os sujeitos que fazem a maior parte do cuidado não profissional, vivenciando de forma concreta a realidade de comunicação com o idoso com demência.
A pesquisa foi realizada no Núcleo de Neurogeriatria de um hospital público da cidade do Rio de Janeiro, com 25 cuidadores principais inseridos no programa de atendimento semanal do local de estudo, no período de agosto de 2005 a abril de 2006.

Deste modo, dentro do MCS, utilizamos com destaque para a produção dos dados as Dinâmicas de Criatividade e Sensibilidade (DCS), que propiciam uma triangulação de dados quando associamos a discussão grupal, a observação participante e a metodologia crítico-reflexiva. Momentos sugeridos: 1) disposição do grupo e a organização do ambiente e material; 2) apresentação da coordenadora como mediadora das discussões do grupo, dos co-produtores dos dados, da temática e da questão norteadora; 3) explicação e operacionalização da dinâmica com distribuição do material; 4) coletivização das experiências individuais produzidas; 5) análise coletiva dos dados com apropriação interativa do conhecimento. Entretanto, na produção dos dados foram acrescidos os passos: 6) pré-análise do pesquisador; 7) devolução ao grupo num segundo encontro; 8) aprofundamento da discussão; 9) e validação do processo de análise grupal, no intuito de garantirmos o atendimento aos objetivos do estudo e aos pressupostos da análise de discurso proposta.

Para isso, optamos por duas dinâmicas de criatividade e sensibilidade. Na primeira chamada de "Corpo-falante", solicitamos que os cuidadores expressassem seu pensamento no papel cartolina através da analogia com o corpo físico sobre a questão norteadora: como você se comunica com o idoso com demência? Foram realizados dois encontros totalizando 256 minutos, aproximadamente, 4 horas. E a segunda chamada de "Almanaque" consiste no uso de recorte e colagem de figuras diversificadas que são disponibilizadas a partir da questão norteadora apresentado aos participantes através do qual cada um constrói a sua própria seqüência de eventos: como eu faço para me comunicar? Porque eu faço assim? Quais os resultados que eu obtenho? A intenção é criar um processo de pensamento-linguagem, aguçando a expressão de cada participante sobre o tema proposto. Nesta segunda dinâmica, houve a necessidade de destacar as situações dos idosos por estágios, portanto, eles foram divididos em três grupos, ocorridos na seguinte seqüência: $1^{\circ}$ - Moderado; $2^{\circ}$ - Avançado; e $3^{\circ}$ - Leve. Para cada estágio foram realizados dois encontros, seis grupos sendo 2 horas para cada, totalizando 12 horas de produção de dados. 
Quanto à organização e tratamento dos dados produzidos, utilizamos a análise de discurso, ${ }^{10-11}$ que propõe as seguintes etapas de análise: $1^{\text {a }}$ Etapa - Passagem da superfície lingüística para o texto (discurso). Ao transcrever as falas, o material discursivo sofre o tratamento dado pelo pesquisador, ou seja, as fitas foram ouvidas e cada sujeito foi identificado, prestando-se atenção em como o discurso foi falado/expressado, para que se pudesse proceder com a materialização do mesmo através dos símbolos lingüísticos (pontuação, exclamação, interrogação, parênteses, reticências, e outros); $2^{\text {a }}$ Etapa - Passagem do objeto discursivo para a formação discursiva. Nesse momento, também se integrou ao relatório as observações participantes realizadas no âmbito grupal (postura do corpo, gestos, choro, risos, pausas, tom de voz), dando materialidade e sentido ao discurso produzido, relacionandoos com a imagem produzida nas dinâmicas; e $3^{a}$ Etapa - Processo discursivo para a formação ideológica. Com base nos objetivos da pesquisa e no referencial teórico adotado, categorizam-se os dados construindo quadros de referências dos discursos, levando o analista a compreender a observação dos processos e os mecanismos constitutivos de sentidos dos sujeitos investigados.

A análise triangulada, favorece o aumento da confiança do estudo, solicitada para aprofundamento dos dados encontrados na pesquisa qualitativa que não podem ser confirmados através de medidas, pois nos interessam os significados, as crenças, as intenções, os conceitos ou valores acerca da comunicação de cuidadores com idosos com demência.

Com relação aos aspectos éticos, foi indispensável a autorização expressa da instituição onde ocorreu a produção dos dados, tendo sido o projeto submetido ao Comitê de Ética em Pesquisa do Hospital, com aprovação sob o protocolo $\mathrm{N}^{\mathrm{o}}$ 014/06. Além disso, todos os participantes assinaram o Termo de Consentimento Livre e Esclarecido, atendendo ao disposto na Resolução N 196/96, do Ministério da Saúde, que trata de Pesquisas com Seres Humanos, depois de informados sobre os objetivos e rumos da pesquisa, bem como de seus direitos como participantes. Solicitamos autorização para gravar as discussões grupais, assim como fotografar as produções artísticas que seriam feitas, garantindo a preservação de seu anonimato.

\section{RESULTADOS: ANÁLISE E DISCUSSÃO DOS DADOS}

A formação da mensagem dos cuidadores é direcionada para expressão dos objetivos/finalidades da comunicação, como: realização de uma atividade prática, ser compreendido/se fazer entender, mantê-lo calmo e tranqüilo, proporcionar bem-estar, interesses econômicos/financeiros entre outros. Assim, necessariamente, os cuidadores se comunicam quando desejam transmitir algo ao sujeito receptor (o idoso com demência). O que o leva a processar a mensagem como um ato intencional de ação comunicativa.

Assim, pelo menos três fatores precisam ser levados em conta na formação da mensagem: o conteúdo, o tratamento e o código. E esses precisam ser distinguidos de duas formas: com os elementos de cada um, e o modo como esses elementos são estruturados. Assim, analisamos os dados na busca de como ocorre a formação da mensagem dos cuidadores (fonte), como realizam o processo de seleção de uma ou outra peça de informação, de um ou outro conjunto de afirmações, de um ou outro conjunto de evidências para codificar a mensagem, podendo escolher este ou aquele conjunto de elementos componentes do código, um ou outro método de dispor os elementos do código, podendo mesmo dispor o conteúdo desta ou daquela forma.

$\mathrm{Na}$ formação da mensagem pelo cuidador surgiu o "uso da palavra" em ocorrência superior ao uso da "expressão não-verbal", mesmo sabendo que esse indivíduo tem comprometimento dos canais de codificação e decodificação por conta dos déficits cognitivos (memória, agnosia, afasia, apraxia e funções executivas).

Por isso, a mensagem utilizada pelo cuidador é acrescida e modificada conforme os estágios da doença. No início, o cuidador refere comunicar-se normalmente, isso devido à negação da doença presente nessa fase. A cuidadora 19 representa seu imaginário, na dinâmica almanaque, com uma figura de três amigas lendo, sorrindo, toda de branco e na figura está escrito 'bem-estar'. O significado da figura é complementado com o discurso: falo com ela normalmente. Mas quando vejo que ela não entende, falo mais devagar mostrando algo para que ela lembre e entenda melhor. Através da fala mesmo [...] e vejo a expressão das perguntas, se parece assustada, ou quando não entendeu, dou um tempo a minha mãe [...] às vezes ela não entende uns negócios 
e fica repetindo (C 19). Percebemos nessa fase que o cuidador, apesar de trazer o falar normalmente, surge logo em seguida a queixa da não compreensão do idoso, a repetição, e os lapsos de memória, mas esses ainda pouco associados à doença, necessitando de orientação profissional.

No discurso apresentado, ocorre também um exemplo do uso da expressão verbal em seu conceito fundamental: "o primeiro aspecto a ser considerado, na comunicação verbal, quando a fala é normal, é a clareza quanto àquilo que desejamos informar". ${ }^{12: 46}$ Portanto, além do cuidador definir o que deseja informar e o que quer atingir com a comunicação, precisa também saber se expressar, clarificar o fato falado, e validar a compreensão do que é descrito, verificando se a compreensão está correta e se ele se fez entender, se aperfeiçoando numa comunicação diferenciada, quando o outro não é um igual no que se refere às habilidades cognitivas.

O uso da expressão verbal é característico dessa fase leve porque o idoso não apresenta dificuldades na expressão da fala, ou seja, no seu sistema fonético, o que em decorrência da afasia ocorrerá mais à frente, como apresentado no discurso: tem uma faca lá azul que é a faca do Seu B. [marido da idosa], então ela cisma com aquela faca [...] ela coloca prá mim e a branca prá ele. Então, quando ela coloca a faca pra mim, eu falo - mas essa faca não é minha! Aí ela fala - Ah é! [...] a faca é do Seu B. Aí ela volta e coloca para ele. Quando o Seu B. está em casa ele irrita muito ela, ele manda ela fazer as coisas e ela não quer fazer e isso deixa ela muito irritada. De resto, pra mim é normal (C 14). Por isso, nessa fase, encontramos as dificuldades de execução de tarefas, como a troca de objetos, a dificuldade com o dinheiro, com a localização no espaço, os lapsos, e o comportamento do idoso de se irritar com suas falhas.

Isto pode ser visto também no fragmento do discurso da cuidadora, a qual sua mãe está com Doença de Alzheimer em estágio intermediário: entendeu? A comunicação é através de palavras, se ela tá bem, se ela já tomou banho, os cuidados que a gente tem pra ela ficar calminha! Pela fala e pelos atos, de botar a comida direitinho, tem até uma bandejinha. Aí eu boto a bandejinha, o paninho, o prato, a sobremesa, o remédio, aí eu dô. Tudo isso eu faço, pra ela ficar legal, ou melhor, do que ela tá (C 1). A comunicação estabelecida entre elas se direcionou mais pelo uso da comunicação verbal, com a finalidade de executar uma atividade prática, entendendo que "comunicar é procurar resposta do receptor.
Qualquer fonte de comunicação se comunica a fim de fazer com que o seu receptor faça alguma coisa, fique sabendo alguma coisa, aceite alguma coisa". 7:67 Como também podemos analisar o desejo da cuidadora que a idosa permanecesse calma, e por isso utiliza uma comunicação orientada para a realidade proporcionando inclusão da idosa nas atividades práticas.

Assim, uma mensagem é um produto físico real do codificador-fonte, ou seja, ela materializa os desejos intencionais dos sujeitos, "quando falamos, o discurso é a mensagem, se escrevermos, a escrita é a mensagem, ao pintarmos, a pintura é a mensagem, quando gesticularmos, os movimentos dos braços, as expressões do rosto são a mensagem". 7:31 Sendo preciso que os cuidadores sejam orientados sobre sua atividade comunicativa como fonte, tornando-os conscientes de que precisam manter o receptor (idoso) ativo durante todo o tempo, escolhendo códigos que o nosso receptor entenda e selecionando elementos de código que lhe chamem a atenção, que lhe sejam fáceis de decodificar e assim atinjam seus objetivos.

Talvez isso explique o aumento da tendência a utilizar mais a expressão não-verbal, à medida que a demência progride e a síndrome afásica se torna mais evidente. Como produzido na imagem da cuidadora de uma idosa em estágio moderado, filha única, professora, capacitada para o trabalho com crianças especiais. Sua imagem representa um homem jogando o celular, objeto moderno de comunicação, no lixo, e na fala apresentada ao lado da imagem, a cuidadora declara que a comunicação com a mãe está piorando. Traz no discurso essa dificuldade de se comunicar: percebo que a comunicação com ela tá indo pro lixo, foi exatamente [...] o cara tá jogando o celular aqui na lata no lixo, às vezes eu me desespero pela repetição de ações negativas, de palavras assim [...] mesmo com todo o processo de falar para ela o que está acontecendo, o que vai ser feito com ela etc (C 18).

Portanto, ao orientarmos os cuidadores a utilizar uma linguagem simples, clara e com frases curtas, estamos trabalhando com a necessidade desses em 'saber conscientemente' como se forma a mensagem falada, para que atinjam seus objetivos com o menor grau de ruídos comunicacionais possíveis.

Mas nem sempre essa orientação vai dar conta da progressão da doença, sendo necessário aprimorar outros mecanismos de formação da mensagem que não seja pela expressão verbal e, isso aumenta à medida que a demência progride, 
e a dificuldade no entendimento do que é falado aumenta no idoso, como trazido na fala da cuidadora de uma idosa em estágio avançado, que usa da imagem de duas mãos se tocando e cita: quando usava o método normal percebia o quando ficava confusa (C 2). Entender e usar a comunicação não verbal, de forma implícita revela o falar perto, o tocar, o olhar, o chamar a atenção, o usar da mímica, ou um conjunto de técnicas comunicacionais.

Como também representado na produção artística da cuidadora de uma idosa em fase avançada: eu faço assim [...] eu falo perto dela. Porque? Porque é só assim que ela me entende [...] Porque tem hora que ela fala que eu tô com a fala enrolada, mas acho que é porque eu falo muito rápido [...] [pausa] (C 3). Ela precisava se fazer entender, e foi falando perto que ela conseguiu, pois quando ela usa somente a fala sem o toque e a pausa, ela não era compreendida e, por conseguinte, não atingia seus objetivos de se fazer entender pela idosa. No discurso, a cuidadora percorre uma trajetória de eventos mediatizadores de um processo crítico-reflexivo, demonstrado ao se questionar: por que eu falo com ela de perto? Pensando no modo como tratava a formação da mensagem.

É importante entender que o código pode ser definido como qualquer grupo de símbolos capaz de ser estruturado de maneira que o conteúdo que se deseja passar tenha significação para alguém. Esses conceitos de elementos e estrutura poderão ser compreendidos, ao exemplificarmos com os idiomas, que são códigos, pois a língua é um código que contém elementos (sons, letras, palavras entre outros) que são dispostos em certas ordens que tem significação, e não terão se 'estruturados' em outras ordens. Código é tudo o que contém um grupo de elementos (o vocabulário), e um conjunto de métodos para combinar esses elementos de forma significativa (a sintaxe). E, se quisermos aprender algum código, devemos examinar os elementos aparentes e procurar os meios coerentes em que os elementos estejam estruturados. Então, o cuidador (fonte) deve agrupar os códigos (verbal, sons, gestos) tratando-os (estratégias comunicacionais) de acordo com o conteúdo (o material da mensagem) que este deseja passar para o idoso (receptor).

Como vimos, podemos definir conteúdo como o material da mensagem escolhido pela fonte para exprimir seu objetivo, este também possui elementos e estrutura. Se o cuidador quer que o idoso realize o banho, deve reunir as informações e estruturá-las em uma ordem que favoreça o entendimento do que se pede na mensagem. As formas escolhidas para dispor as afirmações determinam em parte a estrutura do conteúdo, como tratado no discurso das cuidadoras: mas você tem que respirar fundo, acalmar e - tá bom vai pro banheiro, toma banho... E por ela estar assim perdida, você tem que falar muito mais pausadamente, muito mais tocando, muito mais sabe? Pra ela se acalmar (C 6); ela é difícil! Até de me comunicar! Eu me comunico com ela muito com as mãos, pegando nela, tudo eu tenho que levar ela até o lugar, se eu quiser que ela vá ao banheiro, eu tenho que levar, tirar a roupa dela, botar ela sentada [...] [referindo-se a uma sequiência de eventos necessários para fazer o idoso ir ao banheiro] (C 15).

$\mathrm{E}$ isso se prolonga ao considerar que tratamos de receptores com deformações na estrutura orgânica tanto de fala como de compreensão e, no entanto, necessitam de processo de validação abrangente não restrito ao uso da expressão verbal. Mesmo que a fala e a imagem sejam as mais usadas no nosso cotidiano, neste estudo, a habilidade de associação da expressão verbal a expressão não verbal se torna um caminho favorável no processo de estabelecimento da comunicação com os idosos: aí eu botei uma pessoa não só falando, mas também gesticulando (C 18); é mais até que a boca às vezes, porque às vezes eles falam uma coisa e sente outra (C 1); às vezes um abraço. Às vezes o abraço diz mais que palavras que não vai entrar na cabeça deles (C 4).

A comunicação não-verbal é uma habilidade que pode ser desenvolvida no cuidado com o idoso demenciado, implicando seu uso numa efetividade da comunicação que deveria ser potencializada, mas deve ser contextualizada, pois como vemos na fala de um cuidador, esposo, 82 anos, com um relacionamento matrimonial ruim anterior à doença, o aprimoramento da expressão não-verbal é difícil. Esse cuidador responde o seguinte ao ser questionado pela pesquisadora - O senhor consegue falar alguma coisa com a dona A sem ser pela fala? Não (C10). Pelo toque? Pelo olhar? Pela expressão do rosto? Não. Nada disso. O que eu digo não vale (C 10).

E a comunicação não-verbal só ocorre na interação pessoa-pessoa, ao perceber, ao tocar, ao olhar o outro, e perceber os seus sentimentos, suas dúvidas e dificuldades em relação ao que é falado. ${ }^{7,13}$ Assim, não podemos esperar que o cuidador 10 utilize tal comunicação, pelo histórico-existencial com a idosa, porque ele não está "apto", ou mesmo não lhe interessava, ou ele sequer sabe o que é a utilização da comunicação não-verbal. Não conseguia sequer olhar para a idosa quando lhe dirigia a palavra, quanto mais tocá-la, portanto, o uso da comunicação não-verbal pelos cuidadores tem a ver 
não somente com sua habilidade, mas com o contexto histórico-existencial e familiar dessa relação.

Fatores emocionais continuam a se manifestar mesmo nos sujeitos com problemas cognitivos, por fazerem parte de aprendizados não ligados à cognição introjetados por vias emocionais e ou sócio-culturais nas estruturas psicobiológicas. ${ }^{14-15}$ Daí a importância desses serem contextualizados de acordo com a posição histórico-existencial dos sujeitos envolvidos na situação comunicacional.

Assim, "a comunicação não-verbal só pode ser examinada no contexto em que ocorre porque nem sempre a mensagem tem o mesmo significado para diferentes pessoas e situações" ${ }^{16: 57}$ os cuidadores observam seu uso, e fazem dele instrumentos de avaliação do cuidado prestado 'validando se está tudo bem', ou mesmo, se o idoso necessita de algo, segundo a relação estabelecida: poisé o andar, quando ela tá muito bem, o "andarzinho" dela é mais [...] ela começa a levantar mais o pé e começa a ficar mais suave (C 7); quando ela tá down ela fica se arrastando, e hoje ela se aprontou, foi uma 'ligeireza' no corredor (C 6).

Então, ocorre uma mensagem direcionada a um codificador com dificuldades nas habilidades comunicadoras verbais, tanto na codificadora "palavra escrita e falada" como nas decodificadoras "leitura e audição" e uma crucial tanto para a codificação como para a decodificação "o pensamento ou raciocínio". ${ }^{7}$ Devemos analisar o prejuízo ocorrido pelos transtornos cognitivos para a formação da mensagem, ou seja, uma "comunicação diferente das outras pessoas", como citado no discurso das cuidadoras do grupo de cuidadores de idosos com demência avançada: ela já não consegue se expressar como uma pessoa normal: - Eu quero um pano de prato pra enxugar os pratos, enxugar os talheres [...]. Entendeu? Então, eu tento facilitar (C 9); então, eu queria fazer normal como a gente age com qualquer pessoa e estava dando errado porque ela fica super nervosa, chorava e falava: ah! [...] eu tô maluca mesmo! (C 2).

Apostamos na valorização da comunicação não-verbal para com os idosos com demência, com fundamentação nos estudos que apontam que essa carrega um conteúdo menos consciente que a expressão verbal, ou seja, menos dependente da cognição para sua execução, não envolvendo somente aspectos de memorização. ${ }^{17}$

Ressaltamos que as escolhas na formação da mensagem devem ser feitas conscientemente, pois se não organizadas mentalmente pelo sujeito podem fazer decrescer a efetividade da comunicação, correndo o risco de produzirem ruídos e, conseqüentemente, de não alcançarem os objetivos traçados.

Corroborando com nosso compromisso profissional de ajudar pessoas, e nesse caso, os cuidadores a formarem essa mensagem conscientemente, compreendendo o que se deseja comunicar e como deve ser falado. Por isso, a comunicação deve ser apresentada aos cuidadores como uma ferramenta básica do seu dia-a-dia de cuidado ao idoso com demência, associando ao trabalho que vem sendo desenvolvido pelas enfermeiras nas orientações de estratégias; ${ }^{18-20}$ discutindo a comunicação com os cuidadores de forma problematizadora de sua realidade de cuidado ao idoso, a forma como ele o faz no seu ambiente, e também ampliando o conhecimento sobre seus objetivos intencionais.

\section{CONSIDERAÇÕES FINAIS}

Ao buscarmos, enquanto enfermeiras, conhecer a forma como os sujeitos processam a comunicação, tanto como fonte ou receptor, encontramos uma visão mais ampliada da presença de falhas neste processo. Como por exemplo, se o cuidador não está usando os canais de comunicação outros que não o verbal, se fala rápido, sem contato visual e ou toque; ou mesmo se não percebe os movimentos e expressões do idoso, tentando os associar com sua fala, esses são pontos que podem ser trabalhados e desenvolvidos para uma comunicação efetiva.

Portanto, ao realizarmos a descrição e análise da formação da mensagem dos cuidadores de idosos com demência, no contexto do cuidado no domicílio, percebemos a importância de conhecermos como ela se dá, por sermos profissionais de saúde que, em primeira instância, deve estar comprometido com a promoção do bem-estar e conforto de seus clientes. No caso do cuidador e do idoso, esta promoção se dá pela ajuda que podemos oferecer no sentido de otimizar a relação entre eles, o que favorecerá o cuidado. Cuidado este de alta complexidade porque trata de saber cuidar de idosos com transtornos cognitivos.

Contudo, há que se ajudar os cuidadores a melhor produzir as mensagens emitidas para os idosos, e o que é preciso usar para formar o código. Ao codificarmos a mensagem, escolhemos os símbolos e os organizamos em forma sistemática, para optarmos pelas estratégias comunicacionais a serem desenvolvidas. Ao recebermos a mensagem, a decodificamos procurando traduzir esse código em nosso próprio sistema nervoso, de maneira 
que haja um significado, e essas significações são atribuídas pelas pessoas em seu contexto, que estão nos sentidos corporais contidos no organismo humano de acordo com suas intencionalidades.

Assim, esta pesquisa pode contribuir na prática da área de gerontologia, e em especial na enfermagem, a partir do momento em que nós, enfermeiras, ao entendermos as questões que envolvem a comunicação entre esses sujeitos - cuidadores e idosos com demência - podemos contribuir com a diminuição do grau de estresse dos familiares, gerado pelo cuidado diário aos idosos com demência. Além do que, podemos diminuir as situações extremas de maus-tratos e violência e, inclusive, vislumbrar uma queda de gastos públicos com internações geriátricas. Isto através da ajuda aos cuidadores na descrição de suas experiências, ao tornar familiar o fato de ser a ação comunicativa a base sobre as quais são construídas as necessidades de compreensão mútua e da comunicação efetiva, não se esquecendo dos ruídos e barreiras que podem existir na comunicação.

Este estudo também oferece subsídios ao cuidado de enfermagem geriátrico e, também, de um modo geral, no intento da valorização do estabelecimento de uma comunicação efetiva não só com o idoso com demência, mas proporcionando fundamentos para o exercício profissional da enfermeira no treinamento e orientação de cuidadores sobre a importância do estabelecimento de estratégias para uma comunicação livre de ruídos.

Como também para o ensino de enfermagem, no que tange a necessidade de construção de conteúdos específicos sobre o cuidado de enfermagem ao idoso com demência e sua família, que fundamentem a formação do enfermeiro pautados em investigações da área, especialmente porque trata de sujeitos em uma realidade concreta de viver e conviver com o idoso que experiencia um processo demencial. Os resultados desta pesquisa poderão ser utilizados como referencial para o ensino de cuidados aos idosos, uma vez que esta área caminha para adequação curricular dos conteúdos e das práticas específicas em Gerontologia atendendo às demandas sócio-culturais.

$\mathrm{E}$, além disso, ressalta-se que as contribuições para o cuidado e o ensino de enfermagem na área de gerontologia articulam-se àquelas relacionadas à pesquisa, tão necessária para a construção da ciência da enfermagem. Assim, esta investigação também traz contribuições para a aplicação da teoria da comunicação nas ques- tões de interesse da enfermagem fundamental, como cuidados fundamentais para com os idosos com demência, aplicando, assim, a comunicação como instrumento essencial na interação humana e na relação de cuidado.

Finalizando, ressalta-se que o aspecto central na educação/orientação da enfermeira gerontológica é a comunicação com os idosos, de um modo geral e, em especial, com o idoso demenciado, destacando como prioridade os déficits cognitivos e sua relação com os transtornos de comportamento, e as possíveis formas de "driblar" essas barreiras através do uso da ferramenta comunicacional.

\section{REFERÊNCIAS}

1 Lopes MA, Bottino CCM, Hototian SR. Epidemiologia das demências: análise crítica das evidências atuais. In: Bottino CCM, Laks J, Blay SL, organizadores. Demência e transtornos cognitivos em idosos. Rio de Janeiro (RJ): Guanabara Koogan; 2006. p.23-9.

2 Mendes PBBT. Cuidadores: heróis anônimos do cotidiano. In: Karsch UMS. Envelhecimento com dependência revelando cuidadores. São Paulo (SP): EDUC; 1998.

3 Machado JCB. Doença de Alzheimer. In: Freitas EV, et al. Tratado de geriatria e Gerontologia. Rio de Janeiro: Ed. Guanabara Koogan; 2000. p.133-47.

4 Brucki SMD. Envelhecimento e memória. In: Andrade VM, Santos FH, Bueno OF, organizadores. A Neuropsicologia hoje. São Paulo (SP): Artes Médicas; 2004. p.389-402.

5 Hoffman SB, Platt CA. Comforting the confused: strategies for managing dementia. New York (NY): Springer Publishing Company; 2001.

6 Mailloux-Poirier M. Comunicar. In: Berger LM, Mailloux-Poirier M. Pessoas idosas: uma abordagem global. Lisboa (PT): Ed Lusodidacta; 1995. p.475-502.

7 Berlo DK. O processo de comunicação: introdução à teoria e à prática. São Paulo (SP): Ed. Martins Fontes; 1979.

8 George JB. Teorias de enfermagem: os fundamentos à pratica profissional. 4a ed. Porto Alegre (RS): Artmed; 2000.

9 Cabral IV. O método criativo e sensível: alternativa de pesquisa na enfermagem. In: Gauthier J, Cabral IV, Santos I, Tavares CMM, organizadores. Pesquisas em enfermagem: novas metodologias aplicadas. Rio de Janeiro (RJ): Guanabara Koogan; 1998.

10 Orlandi EP. Análise de discurso: princípios e procedimentos. 5a ed. Campinas (SP): Pontes; 2003.

11 Maingueneau D. Novas tendências em análise do discurso. 3a ed. Campinas (SP): Pontes; 1997. 
12 Silva MJP. Comunicação tem remédio: a comunicação nas relações interpessoais em saúde. 2a ed. São Paulo (SP): Ed. Loyola; 2003.

13 Renzi E. Agnosias visuais. In: Nitrini R, Caramelli P. Neuropsicologia: das bases anatômicas à reabilitação. São Paulo (SP): FMUSP; 1996.

14 Cummings, JL. The neuropsychiatry of Alzheimer's disease and related dementias. Los Angeles (CA): CRC Press; 2002.

15 Stefanelli MC. Comunicação com paciente: teoria e ensino. 2a ed. São Paulo (SP): Robe Editorial; 1993.

16 Isaacowitz DM, Charles ST, Carstensen LL. Emotion and cognition. In: Craik FIM, Salthouse TA, organizadores. The handbook of aging and cognition. 2a ed. Mahwah (USA): Lawrence Erlbaum Associates; 2000.
17 Marcon SS, Andrade OG, Silva DMP. Percepção de cuidadores familiares sobre o cuidado no domicílio. Texto Contexto Enferm. 1998 Maio-Ago; 7 (2): 289-307.

18 Gonçalves LHT, Silva YF, Pfeiffer S. O cuidado do idoso fragilizado e de seus cuidadores no contexto domiciliário. Cogitare Enferm. 1996 Jul-Dez; 1 (2): 39-47.

19 Santana RF, Santos I, Caldas, CP. Cuidando de idosos com demência: um estudo a partir da prática ambulatorial em enfermagem. Rev. Bras. Enferm. 2005 jan-fev; 55 (1): 44-8.

20 Peltzer MT, Fernandes MR. Apoiando a família que cuida de seu familiar idoso com demência. Texto Contexto Enferm. 1997 Maio-Ago; 6 (2): 339-44. 